\title{
The Business Case Roadmap - BCR: from the Idea to the Business Case
}

\section{Breno de Paula Andrade Cruz}

VIEIRA, V. V.; SILVA, S. C. The Business Case Roadmap - BCR: from the Idea to the Business Case, Lisboa: Conjuntura Actual Editora, 172p.

O livro The Business Case Roadmap - BCR: from the Idea to the Business Case é o primeiro volume da coleção The Business Case Roadmap - BCR e foi publicado em 2018 pelos professores portugueses Vitor Verdelho Vieira e Susana Costa e Silva. A experiência de Vitor Verdelho Vieira como co-fundador de diversas empresas desde 1989 e como professor visitante na Católica Porto Business School (CPBS) se junta à experiência de Susana Costa e Silva (como professora da mesma instituição, coordenadora do Mestrado em Marketing e com mais de 100 textos e livros publicados) para escreverem um excelente livro didático que pode ser usado por empreendedores(as) e por professores(as) de graduação para ensinarem como partir de uma ideia para fazer com que essa ideia se transforme em um modelo de negócio (documento executivo formal - Business Case). Se o Plano de Negócios (Business Plan) é um documento extremamente detalhado, o Modelo de Negócios traz bem menos detalhes - mas não menos importante.

No que diz respeito à trajetória acadêmica e profissional dos autores, há algo em comum que os une além de uma amizade de muitos anos: (i) a docência no MBA e na formação executiva da CPBS ministrando a disciplina Business Plan; e (ii) a consultoria na Porto Design Factory - um ponto de encontro de 20 escolas de quatro continentes com o objetivo de cooperação no desenvolvimento de projetos inovadores voltados ao empreendedorismo, do Instituto Politécnico do Porto.

Recebido em: 04/04/2020

Individualmente, Vitor Verdelho Vieira e Susana Costa e Silva têm suas empresas de consultoria e há anos atuam promovendo a interlocução entre a academia e as empresas em Portugal. Recentemente, Vitor fez parte da equipe que definiu o plano estratégico

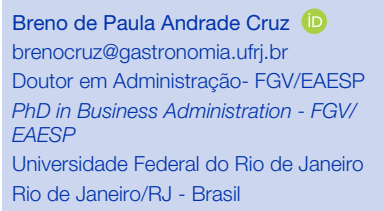

Breno de Paula Andrade Cruz brenocruz@gastronomia.ufrj.br Doutor em Administração- FGVIEAESP EAESP Rio de Janeiro/RJ - Brasil Aprovado em: 10/07/2020 
para os laticínios dos Açores (uma das principais atividades do arquipélago dos Açores). Já Susana, coordenou o Plano de Marketing Territorial da Região do Tâmega e Sousa e tem colaborado com a Associação dos Produtores de Calçados Portugueses - nomeadamente tentando conhecer o efeito do país de origem do calçado português nos mercados internacionais. Essas experiências dos autores parecem torná-los mais sensíveis às demandas do mercado em relação à academia, pois atuam, como consultores, diretamente na resolução de problemas e apresentação de soluções para importantes organizações portuguesas (designadamente as mais representativas do tecido industrial português).

Minha opção pela escrita da resenha do livro ocorre a partir de duas perspectivas: (i) profissional e (ii) pessoal. Assim, minha atuação como professor da disciplina 'Planejamento Estratégico em Alimentação' no curso de bacharelado em Gastronomia da UFRJ me fez refletir sobre meu papel como professor de uma disciplina que não é central na formação dos estudantes deste bacharelado, e, assim, eu não deveria aprofundar temas numa perspectiva epistemológica em relação ao Planejamento Estratégico e à Estratégia. Todavia, não deveria me furtar à teoria nas discussões em sala de aula. Ademais, The Business Case Roadmap - BCR: from the Idea to the Business Case - embora em língua inglesa, de certa maneira me garante, enquanto docente, a existência de teoria sobre os temas tratados; mas, ao mesmo tempo, embora não simplista, não se aprofunda em questões epistemológicas daqueles temas abordados em seu conteúdo. Assim, é um conteúdo que se adequa perfeitamente à minha atuação profissional na graduação por meio de uma perspectiva tanto prática quanto teórica.

Opto por não fazer aqui uma tradução livre do Inglês para o Português pois ficaria talvez extensa e estranha. Todavia, é importante destacar a utilização do termo roadmap - que é uma decisão acertada pelos autores, uma vez que este termo remete justamente à ideia de uma trajetória a ser seguida com um começo, meio e fim. Ter essa divisão por meio de um roadmap tem duas implicações interessantes: (i) na perspectiva do ensino - o passo a passo é uma importante estratégia didática ao se ensinar um conteúdo como esse, podendo ajudar docentes a construírem o conhecimento com os graduandos; e (ii) na perspectiva gerencial - um(a) empreendedor(a) consegue refletir sobre os passos e tornar mais robusta, e com possibilidade de sucesso, a abertura de um empreendimento. Por isso, tanto para profes- 
sores(as) de gestão que lecionam Planejamento Estratégico, Plano de Negócios ou disciplinas afins quanto para empreendedores(as) este é um livro relevante, além de possuir uma leitura agradável.

The Business Case Roadmap - BCR: from the Idea to the Business Case é dividido em 21 passos que norteiam inicialmente a reflexão do(a) leitor(a) em relação (a) às diferentes opções para abrir um novo negócio e (b) a escolha da ideia, passando pela (c) avaliação do mercado e o (d) processo de inovação, até chegar no (e) desenvolvimento e implementação de um modelo de negócio. Algumas ferramentas e teorias relativamente consolidadas em Administração e no mercado são apresentadas, tais como: evolução do ciclo de vida do negócio; estratégia, missão, objetivos e metas; metodologia $5 \mathrm{~W} 1 \mathrm{H}$ à luz da comunicação com investidores de uma startup; Pirâmide das Necessidades de Maslow; Fatores de Sucesso; Escolha da Equipe; Modelo de Ikigai; Modelo de Negócio; Modelo Canvas; Avaliação do Mercado; e Inovação.

A partir destas e outras teorias apresentadas no livro pelos autores, The Business Case Roadmap - BCR: from the Idea to the Business Case tem como objetivo discutir a necessidade de aprofundar a ideia de um negócio e não necessariamente abordar sua execução. E para estudantes de Administração ou para empreendedores(as), aprofundar a ideia de um negócio é consideravelmente relevante - visto que leigos muitas vezes "passam com as carroças na frente dos bois" e executam a operação de um negócio sem planejá-lo. Ressaltar a importância do planejamento do negócio considerando as teorias existentes é essencial para o sucesso de empreendedores

Antes de iniciar a escrita desta resenha me propus a reler o livro e a escolher entre ferramentas e teorias cinco conteúdos que me chamaram a atenção pela inovação da abordagem ou por meu desconhecimento (e assim comunicar a outras pessoas este conteúdo que até então era novo para mim). Desta forma, os cinco conteúdos que discuto a seguir são: Missão, Modelo de Ikigai, Cálculo do Target Market, Matriz de Inovação e a Diferença entre um Modelo de Negócio e um Plano de Negócios. Para estes conteúdos escolhidos nesta resenha, Vitor Verdelho Vieira e Susana Costa e Silva vão às publicações de Kaplan, Norton e Barrows Jr. (2008), Zafar (2010) e Weinberg e Mares (2015), Satell (2015) para construírem seus argumentos- textos que são reconhecidos nas temáticas abordadas pelos autores. 
Em relação à Missão, é interessante destacar que os autores fogem da clássica definição "razão de ser da empresa" e consideram dois aspectos: (i) o presente e o futuro para que (ii) gestores e staff tenham foco sobre onde chegar. Considero que estes dois aspectos abordados pelos autores se encaixam perfeitamente naquilo que considero ser importante em um texto de missão organizacional - deixar claro (a) o ramo de atuação da empresa, (b) os valores organizacionais e os (c) stakeholders. O termo "presente e o futuro" se associa aos valores organizacionais e ao ramo de atuação bem como "gestores e staff" se associa aos stakeholders de uma empresa. Um quadro resumo na página 51 do livro ajuda a deixar ainda mais clara a diferença entre Valores Organizacionais, Visão, Missão e Propósito Empresarial que juntos formam o DNA da empresa.

O Modelo de Ikigai foi algo que me despertou interesse e a pesquisa após encontrá-lo no livro. Embora seja tratado na coleção como um modelo para identificar os candidatos mais alinhados aos objetivos da empresa, este conceito nos faz refletir sobre nossos objetivos pessoais individuais. Será que amamos o que fazemos? Será que somos bons no que fazemos? Embora seja um livro técnico, essas reflexões aparecem quando observamos a mandala Ikigai na página 86. Para os professores Vitor Verdelho Vieira e Susana Costa e Silva, a mandala Ikigai ajuda a escolher um candidato que esteja alinhado com o resto da equipe de trabalho.

Em um contexto em que as polarizações ideológicas estão cada vez mais presentes na sociedade brasileira, de fato pensar na utilização desta filosofia japonesa pode ser uma estratégia eficiente de alinhamento de objetivos, perspectivas e objetivos de vida de pessoas de uma equipe que inicia um negócio. É necessário atentar para o fato de um alinhamento ideológico do funcionário à empresa não ferir direitos humanos ou prover qualquer tipo de discriminação a um indivíduo; para assim atuar na perspectiva da ética social e também a empresa não sofrer com querelas judiciais. Por exemplo, escolher um funcionário vegano para uma loja de produtos orgânicos tem relação com os valores da empresa e do indivíduo. Todavia, excluir um candidato LGBTQIA+ por ser quem ele(a) é, pode sim sugerir uma conduta sem orientação para responsabilidade social corporativa (embora estivesse relacionado à ideia de alinhamento dos valores de empresa conservadora ao conflito em relação aos valores dos funcionários - conforme evidencia o modelo lkigai). Logo, esse modelo não pode ser usado para excluir um indivíduo. 
Ao avaliar o mercado, os professores portugueses são muito didáticos ao usarem o exemplo de um restaurante em uma universidade para definirem o Target Market. À luz das explicações teóricas apresentadas no livro, farei uma transposição do exemplo para realidade brasileira a partir da utilização de um contexto real para a Universidade Federal de Viçosa (UFV) ao considerarmos a abertura de uma cantina mineira junto ao espaço do DCE (Diretório Central dos Estudantes). Viçosa (MG) tem aproximadamente 80 mil habitantes. A UFV, entre estudantes de graduação e pós-graduação, docentes e técnicos, tem um público aproximado de 18 mil pessoas.

Portanto, 18 mil pessoas fariam parte do mercado potencial disponível. Destes, em torno de 3 mil pessoas almoçam no restaurante universitário diariamente. Assim, inicialmente, o mercado total que esta cantina pode atender é de 15 mil pessoas. Todavia, destes 15 mil existem pessoas com características diferentes de consumo e intenção de compra que podem querer algo mais sofisticado, que têm o costume de almoçar em casa, que estão de dieta e levam marmita ou que fazem lanches rápidos. Deve-se, então, estabelecer um percentual deste mercado que pode ser efetivamente atendido. Se estabelecemos $10 \%$, temos 1.500 pessoas que podem almoçar na cantina. E, a partir desse número, analisa-se a capacidade operacional de entrega do serviço e define-se quantas refeições conseguem ser entregues. Se a capacidade máxima de operação permite 200 marmitas na semana e se cada uma é vendida a $\mathrm{R} \$ 10,00$, o Target Market é $\mathrm{R} \$ 2.000,00$ por semana.

A inovação é um tema discutido pelos autores e uma pergunta é deixada por eles para reflexão dos(as) leitores(as): qual é a diferença entre inovação e invenção? Vitor Verdelho Vieira e Susana Costa e Silva respondem essa pergunta informando que em negócios a invenção é a criação de um produto, dispositivo ou processo completamente novo; e, a inovação é o processo de (re)pensar ou mudar processos ou produtos já existentes. Deixar claro essa diferença é importante para que se compreenda a Matriz de Inovação - o quarto conteúdo que destaco nesta resenha.

A análise da Matriz de Inovação pode ser realizada de maneira semelhante à Matriz BCG - considerando os eixos vertical e horizontal. No eixo horizontal tem-se 'o domínio das habilidades requeridas para solucionar o problema' - sendo duas categorias possíveis: (i) bem definido e (ii) não definido; e no eixo vertical observa-se a 'definição do problema' - (a) se está bem definido ou (b) se não está bem definido. Da interação das duas possibilidades para cada eixo surgem as categorias de 
inovação, que podem seguir uma sequência da primeira para a quarta: (i) Pesquisa Básica, (ii) Inovação Disruptiva, (iii) Inovação Radical e (iv) Inovação de Sustentação. Desses tipos, a Inovação de Sustentação é aquela que faz com que o produto continue no mercado sendo bem quisto e bem avaliado. Innovation Funnel (Funil de Inovação) é outro conceito que não é abordado pelos professores e que pode agregar no entendimento sobre inovação para leitores que queiram aprofundar sobre fases de inovação em produtos ou processos.

Os autores portugueses usam da dicotomia de algumas características para explicarem as diferenças entre um Modelo de Negócio e um Plano de Negócios, por exemplo: (a) um Plano de Negócios é mais denso, apresenta mais informações quantitativas e gera maior confiança em função de um maior número de páginas. Já o Modelo de Negócios é mais rápido para ser lido, mais fácil para ser atualizado ou modificado e é mais executivo - é endereçado a aqueles que têm interesse em compreender de maneira mais rápida o contexto. Na página 140 é apresentado um quadro com 9 dicotomias. Todavia, não há classificação das dimensões destas categorias e a segunda dicotomia não parece ser uma dicotomia - e por isso apresento no Quadro 1 as oito dimensões na primeira coluna (que não são explícitas para o leitor) e que geram as dicotomias que são bem apresentadas por essas dimensões na diferenciação dos conceitos.

Quadro 1 As dimensões das dicotomias entre Modelo de Negócios e Plano de Negócios apresentadas no livro The Business Case Roadmap - BCR: from the Idea to the Business Case

\begin{tabular}{|c|c|c|}
\hline Dimensão & Modelo de Negócio & Plano de Negócio \\
\hline $\begin{array}{l}\text { Tamanho do } \\
\text { Negócio }\end{array}$ & $\begin{array}{l}\text { Preferência para o } \\
\text { desenvolvimento de } \\
\text { pequenos negócios }\end{array}$ & $\begin{array}{c}\text { Geralmente indicados para o } \\
\text { desenvolvimento de grandes } \\
\text { negócios }\end{array}$ \\
\hline $\begin{array}{c}\text { Foco do } \\
\text { Documento }\end{array}$ & Desenvolvimento do negócio & Apresentação do negócio \\
\hline $\begin{array}{c}\text { Foco da } \\
\text { Comunicação }\end{array}$ & $\begin{array}{l}\text { Geralmente para a equipe } \\
\text { interna }\end{array}$ & $\begin{array}{l}\text { Investidores e demais } \\
\text { stakeholders }\end{array}$ \\
\hline $\begin{array}{l}\text { Tamanho do } \\
\text { Documento }\end{array}$ & $\begin{array}{c}\text { De duas a três páginas com } \\
\text { anexos }\end{array}$ & $\begin{array}{c}\text { Mais de } 80 \text { páginas com } \\
\text { anexos }\end{array}$ \\
\hline
\end{tabular}




\begin{tabular}{|ccc|}
$\begin{array}{c}\text { Modificações } \\
\text { no documento }\end{array}$ & Fáceis e rápidas & $\begin{array}{c}\text { Mais difíceis e consomem } \\
\text { tempo para serem realizadas }\end{array}$ \\
$\begin{array}{c}\text { Divisão do } \\
\text { Trabalho na }\end{array}$ & $\begin{array}{c}\text { Envolve todo o time em todas } \\
\text { as partes do documento }\end{array}$ & $\begin{array}{c}\text { A divisão de trabalho pode ser } \\
\text { realizada para que diferentes } \\
\text { autores e suas expertises. }\end{array}$ \\
$\begin{array}{c}\text { Dados e } \\
\text { Forma }\end{array}$ & $\begin{array}{c}\text { Existência de infográficos e } \\
\text { tabelas }\end{array}$ & $\begin{array}{c}\text { Explicações descritivas são } \\
\text { geralmente as mais ideais }\end{array}$ \\
$\begin{array}{c}\text { Conhecimento } \\
\text { da Equipe }\end{array}$ & $\begin{array}{c}\text { Todo o time deve conhecer o } \\
\text { documento }\end{array}$ & $\begin{array}{c}\text { Nem todo o time tem } \\
\text { conhecimento de todas as } \\
\text { partes do documento }\end{array}$ \\
\hline
\end{tabular}

Fonte: elaborado a partir de Vieira e Silva (2018, p. 140).

A leitura do quadro proposto por Vitor Verdelho Vieira e Susana Costa e Silva (p. 140) e reformulado a partir das dimensões que propus na primeira coluna do Quadro 1 pode ajudar leitores a sumarizarem as diferenças entre os 'Modelos de Negócio' e os 'Planos de Negócio'. Entender essas dimensões é essencial para o(a) empreendedor(a) ter maior eficiência no processo de construção de uma proposta endereçada aos investidores - principalmente se a proposta for de uma startup. Assim, considerando as características contemporâneas da nossa sociedade em que o consumo da informação ocorre em uma velocidade acelerada, entender como se comunicar com investidores (por meio de um modelo de negócio ou de um plano de negócio) é essencial para futuros(as) empreendedores(as) que buscam capital externo.

A abordagem apresentada pelos professores portugueses em The Business Case Roadmap - BCR: from the Idea to the Business Case se diferencia dos demais livros de Plano de Negócios pelo fato dos autores terem a preocupação com a prática da elaboração de uma ideia de sucesso sem que seja uma abordagem simplista. Ter um conteúdo detalhado (não ser simplista) não impactou num exagero de sofisticação nas análises e teorias - o que poderia motivar o(a) leitor(a) a parar a leitura e deixar o livro na estante. As muitas tabelas, quadros e ilustrações acabam por tornar a leitura mais fascinante e menos acadêmica - embora exista teoria. No entanto, a forma como a teoria é apresentada torna o processo de comunicação dos autores com os leitores mais fluido. 
Os autores resumem que a definição de um modelo de negócio passa pela ideia, pelos clientes, pela equipe e pelo comércio/negócio. Existem ainda dois outros exemplares da coleção assinada por Vitor Verdelho Vieira e Susana Costa e Silva, são eles: The Business Case Roadmap - BCR: how to Implement the Business Case: the execution challenge (volume 2) e The Business Case Roadmap - BCR: how to expand Business Case for growth and avoid pitfalls (volume 3). Se neste primeiro volume o foco é na ideia do negócio, os volumes seguintes focam na execução da ideia e na possibilidade de crescer e gerenciar possíveis armadilhas do mercado.

A coleção The Business Case Roadmap parece de certa forma interessar a alguns leitores e leitoras brasileiras - vide a entrevista publicada no International Journal of Business \& Marketing (da ESPM) em Dezembro de 2019 em que os autores do livro discutem o papel de Portugal como a nova incubadora global de startups; e, resumidamente, falam da coleção dos três livros para os entrevistadores Miriam Salomão e Sergio G. Moraes (2019).

Há que se destacar aqui os impactos profissionais e sociais da leitura desta obra. Parecem mais evidentes os impactos profissionais para professores(as) e discentes de cursos de graduação em Administração ou em cursos em que a disciplina Plano de Negócios é lecionada, pelo fato de sistematizar teorias a partir de um roteiro a ser considerado na abertura de uma empreendimento. Há também a possibilidade de impactos sociais a longo prazo, se o livro for adotado por docentes. Em cursos em que estudantes buscam qualificação para empreenderem com mais segurança (técnica), as teorias discutidas em The Business Case Roadmap - BCR: from the Idea to the Business Case podem tornar mais robustas as ideias de jovens empreendedores, e, assim, diminuir o risco de fechamento do empreendimento nos primeiros anos.

Se por anos ouvimos que o Brasil era o país que mais possuía empreendedores, sendo também o país com o maior número de negócios fechados nos dois primeiros anos, podemos construir juntos por meio da literatura em Administração e com o apoio de organizações como o Sebrae, um contexto mais profissional embasado em experiências como as de Vitor Verdelho Vieira e Susana Costa e Silva. Eles, como consultores e professores de uma renomada Escola de Administração em Portugal, trazem em um livro escrito por acadêmicos abordagens teóricas que agregam valor também aos leitores não-acadêmicos e aos empreendedores(as). 
Assim, na perspectiva gerencial, The Business Case Roadmap - BCR: from the Idea to the Business Case organiza conceitos e sugere um caminho a ser seguido a fim de diminuir o fracasso na abertura de um negócio - e isso por si só já é uma relevante contribuição para empreendedores(as) que investem o capital e suas vidas na abertura ou no recomeço de uma empresa. Contudo, o livro também agrega valor ao docente por sistematizar conceitos e teorias de outras áreas e vivências (como o caso da Matriz de Inovação e o Modelo Ikigai), atualizando ferramentas contemporâneas que impactam diretamente na aprendizagem dos discentes. Essa atualização do docente ao contexto da produção do conhecimento em Administração, alinhada ao contexto das tecnologias e ferramentas digitais disponíveis na Internet são elementos necessários no dia a dia em sala de aula - seja em disciplinas de cursos de Administração ou também em outros cursos de áreas afins.

Boa leitura!

\section{Referências}

BASKIN, K. Corporate DNA: Learning from Life. London: Routledge, 2011.

KAPLAN, R. S., NORTON, D. P. e Barrows Jr., E. A. Developing the Strategy: Vision. Value Gaps, and Analysis, Harvard: Harvard Business School Publishing, 2008.

SALOMÃO, M. e MORAES, S. G. Portugal, a nova incubadora global de startups. International Journal of Business Marketing, v. 4, n. 2, p. 03-07, 2019.

SATELL, G. Mapping Innovation: a Playbook for Navigating a Disruptive Age. Chicago: Mc Graw Hill Education, 2017.

ZAFAR, N. Market Research on a Shoestring. Cupertino: Five Mountain Press, 2010.

WEINBERG, G. e MARES, J. Traction: How Any Startup Can Achieve Explosive Customer Growth. New York: Portfolio / Penguin, 2015.

\section{Agradecimento}

Ao Engenheiro de Produção Guilherme Thadeu de Andrade Rocha pela troca de conhecimento em relação ao tema Inovação e as teorias relacionadas. 